\title{
CENTRALISED DIAGNOSTICS OF ELECTRONIC AND ELECTRIC EQUIPMENT IN VEHICLES, ENGINE LIGHTING EQUIPMENT TESTING
}

\author{
Petr Ježdík, Jiří Novák \\ Czech Technical University, Faculty of Electrical Engineering, Department of Measurement, \\ Prague, Czech Republic, \\ jezdip1@fel.cvut.cz,jnovak@fel.cvut.cz
}

\begin{abstract}
Today's diagnostic systems used in vehicles are based on separate diagnostic subsystems for each electronic or electric device. The basic idea of the project is to develop a centralized diagnostic method to cover most of functional systems. The proposed method would expedite the overall testing time and bring other significant advantages such as savings on test equipment. This paper deals with engine lighting equipment testing technique.

The fundamental idea is that both electronic and electric devices in a vehicle have a relationship to communication control busses. Each device can also be described as an electrical consumer with its typical power consumption characteristics. Hence, the proposed diagnostic method is based on investigating transient profile on power lines of a tested device whilst changing its state from off to on. The short time Fourier transform (STFT) processing is then applied to analyze the gained signal. The analysis results evaluate the condition of the engine lighting equipment.
\end{abstract}

Keywords: Centralized diagnostics, engine lighting equipment, integral transforms, spark gap model

\section{INTRODUCTION}

Automotive engine systems diagnostics is generally based on decentralized concept. Most car manufacturers use their own proprietary diagnostic technology by utilizing a system of individual probes. There is a public standard OBD (OBDII) [4] to provide generic diagnostic information about the real condition of devices. The faults covering provided by the OBD is relatively high. Looking for the new ways of diagnostics could therefore seem to be redundant. Nevertheless, there are cases the OBD provides the diagnosis indirectly or less exactly, especially in terms of fault localization. For example if a fault in engine is detected, OBD doesn't say where the fault exactly is, if it is in injection valve, lighting candle, cables or transformer. In case of non-lighting candle it is not clear whether the reason is the candle connection, cable insulation or dirty discharger. The centralized diagnostics, where the power consumption of particular devices is processed, can determine the point of fault exactly.

One part of the project focuses on detection of the correct function of engine lighting equipment (transformer, cables and lighting candles). In this case it means to design and use of a technique that decompose and analyze the complete electric power consumption signal of engine. Every functional block of engine adds its power consumption part to whole engine signal. A typical example of such a complex signal with no fault is shown in Figure 1. This signal represents other engine support devices such as gas pump, valves, lambda probe preheating, active coal tank valve and so on. The methods focused on obtaining high-quality real state signs of lighting equipment are the main goal of this part of project.

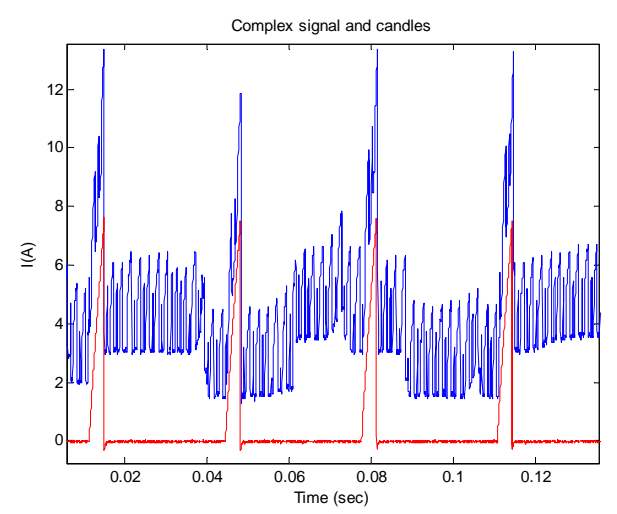

Fig. 1 - Typical (no faults) engine current consumption complex signal, lighting candles current highlighted.

At first, the model of typical lighting system in Matlab - Simulink environment has been made and the faults simulated. The model is based on knowledge of the system circuit scheme and on 
estimation of sparks ignition and non-destructive insulators breaking down behavior.

The real model of lighting system is then created in laboratory conditions and the typical faults stimulated. The short time Fourier transform (STFT) is used to time localization of fault. The results coefficients of STFT in fault time are then processed to final kind of fault identification.

A Škoda Fabia car $1.416 \mathrm{~V}$, its electric and topologic scheme of all functional blocks and released functional information from manufacturer are used to develop the diagnostic technique. All data are measured at that car. There are measured data on new model of Škoda Fabia II car as well. The lighting structure used by manufacturer in the new model differs from the old one. Results of the presented technique on both engines are discussed below.

\section{LIGHTING EQUIPMENT}

Almost all automobile manufacturers already left the classic mechanical concept of high voltage distribution in ignition systems. The new concept uses the Distributorless Ignition System (DIS) based on semiconductor switch devices. It means the highvoltage secondary winding of ignition transformer is directly connected to each of the sparks. There is not possible to use only one ignition coil for all the sparks, cause simultaneous lighting all the sparks in four-stroke engines can't work correctly. It consequents in using more ignition coils. Actually there are two basic kinds of constructions of DISs called Double-Ignition-Coil (DIC) and SingleIgnition-Coil (SIC).

The basic electric principle of DIC can be seen in Fig.2. Two sparks flashing are simultaneously in two

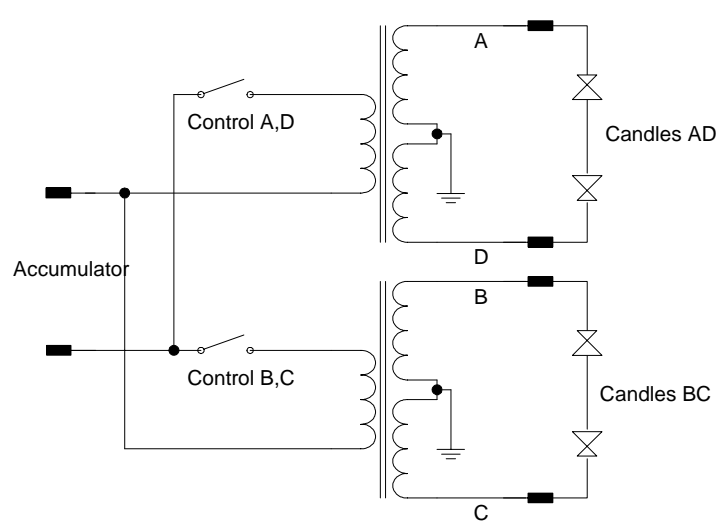

Fig. 2 - Simple electric schema of DIC.

engine cylinders, but they are in different phases. This principle can be used only in engines with even number of cylinders. This solution has the advantage in costs but the new trend is in SIC because of various control possibilities and the use-capability in the odd number cylinder engines too. The principle of SIC uses the same number of transformers as the sparks. See Fig. 3.

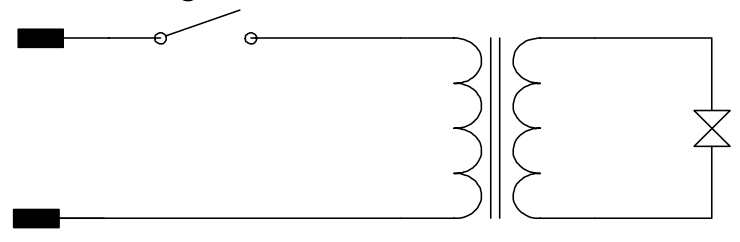

Fig. 3 - Simple electric schema of SIC.

A high voltage secondary coil transformer, carbon or copper cables and lighting candles present the lighting equipment in the car. The diagnostic system should recognize following states: "All OK", "candle fault" - the lighting number of candle and kind of fault, "cable fault" - the cable number and kind of fault and "transformer fault" - the kind of fault.

\section{MODEL}

Spark gaps or Electrical Surge Arrestors (ESAs) [5] are highly nonlinear devices whose function is to stop transient surges on DC or AC power-supply lines. Such transients can be caused by lightning strikes, motor starts, etc. In other cases, spark gaps can also be used repetitively in ignition-type circuits. A spark gap is made of two electrodes that face each other across a short distance. The gap is filled with air or an inert gas like argon or neon. If the voltage applied to the ESA is below its striking voltage (or avalanche potential), the current flowing through the ESA is close to zero. Once the striking voltage is attained, the voltage across the ESA suddenly collapses to a value called the glow voltage. If the current still increases, the ESA voltage decreases further to a level called the arc voltage, where it stays until the surge passes. At this point, the ESA stays conductive until its current falls below a sustaining value in a manner similar to a thyristor. See Fig.4.

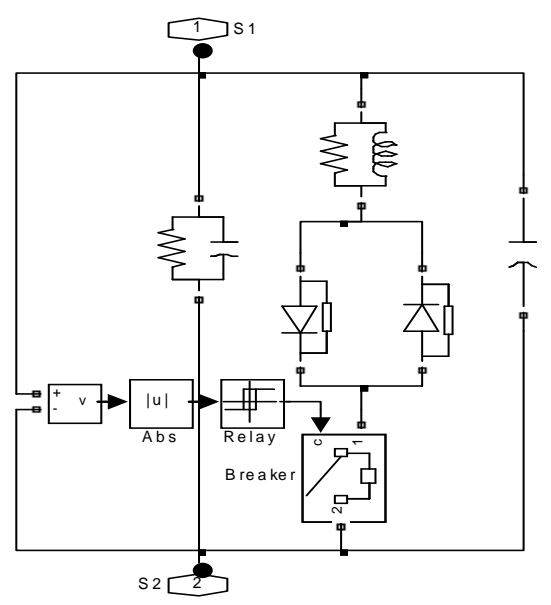

Fig. 4 - Simulink model of spark gap. 
Using the spark gap model and PowerSim Library in Matlab Simulink whole electrical scheme of the ignition systems can be modeled. For instance, the DIC structure is shown in Figure 5.

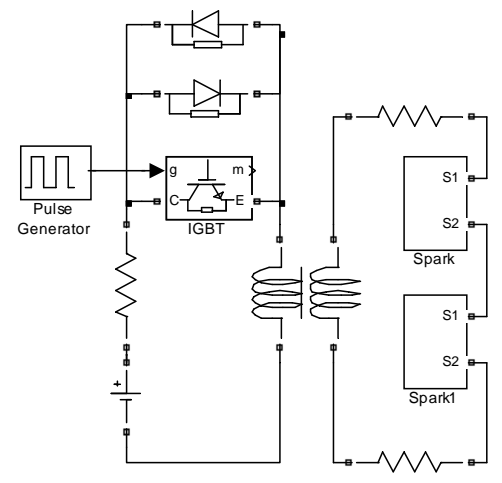

Fig. 5 - Double Ignition coil structure.

The signal of transformer primary current when the system is working properly is shown in Figure 6. All the energy accumulated in transformer is dissipated in flashing and real transformer windings. The primary current though the transformer has very similar shape to first order system step response.

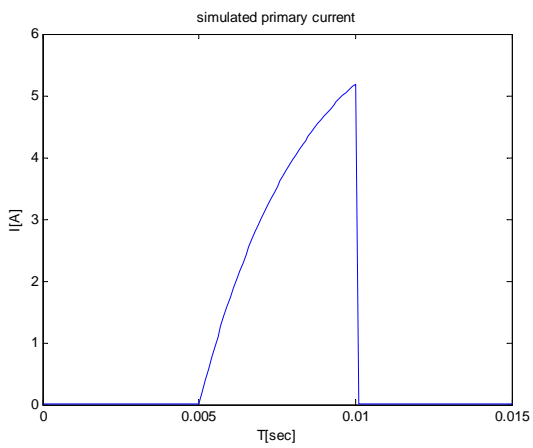

Fig. 6 - Primary ignition transformer current.

Generally the faults in the ignition systems can be described as accidental electric breakdown of insulators. It covers the dirty dischargers, broken insulators or unplugged cables as well. By increasing the glow voltage values and/or changing the electrical parameters of the other circuits the typical faults can be simulated.

Basically the higher glow voltage in spark gap causes the whole energy accumulated in transformer can't dissipate in transformer winding and spark gaps fast enough and the voltage on primary coil grows over the protection voltage thresholds of semiconductor switch. It results in the damped oscillation added to the first order step response of the primary current in transformer. See Fig 7.

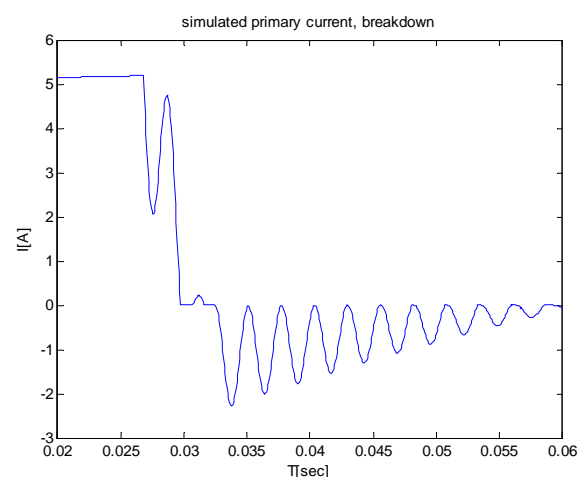

Fig. 7 - Simulated dumped transition due to higher glow voltage of spark gap.

\section{DIAGNOSTIC}

\section{DIAGNOSE SOURCES}

A list of information sources, knowledge and limitations that take part in a lighting equipment diagnostics process in real car follows.

\section{MEASUREMENT}

The overall engine power consumption signal is measured all the time the engine is running. The required sampling frequency is about $10 \mathrm{kHz}$ for the first type of fault classification. A higher sampling frequency, approx. $10 \mathrm{MHz}$, can bring better opportunity for more detailed identification of the fault. A time position of concrete spark is recognized by signal processing methods, because there is no trigger source available with low enough jitter.

\section{CAR'S INFORMATION SYSTEMS}

The RPM (Revolutions Per Minute) information is captured at the CAN bus by an acquisition system. One engine revolution comes up to two transient effect of candle in complex signal. The uncertainty of actual RPM information depends on information cycle period on the CAN bus.

\section{ELECTRIC BEHAVIOR OF SUBJECTS}

Different cable lengths at the transformer-cablescandles configuration can be used to make out the branch of the cable where the fault happens. Even if the cables are made with the impedance independent to its length and the same for all cables, another time response caused by reflection at the end of cable (candle) can be supposed.

The power consumption characteristics of the lighting equipment group at supposed measuring point in car conform to step transient response of primary coil of transformer, i.e. first order system step response [3]. The light on a spark is generated by controlled step down when the transformer coils 
are fully charged. The lights are generated on both sparks in pair simultaneously but only one of them has the ignition effect.

The damped transients respective the electric behavior of the group with simulated fault states were measured on real model and also on the car. Ten faults-free sets of cables, sparks and transformers were measured. Then the typical fault states were arranged and these sets were measured again. For example, a dirty discharger by oil, different sizes of discharger air gap or short discharger effects were measured for sparks. Cable breakdown in different parts of cables were simulated and measured by breaking the insulator and placing the cable close to metal coupling plate. The transformer faults haven't been simulated yet. The full report can be found in [2]. The main conclusion of this work is that the developed model of an electrical behavior of the lighting equipment very well equals to the real system behavior for all states (with and without faults). The example of two insulator breaks is shown in Fig.8.

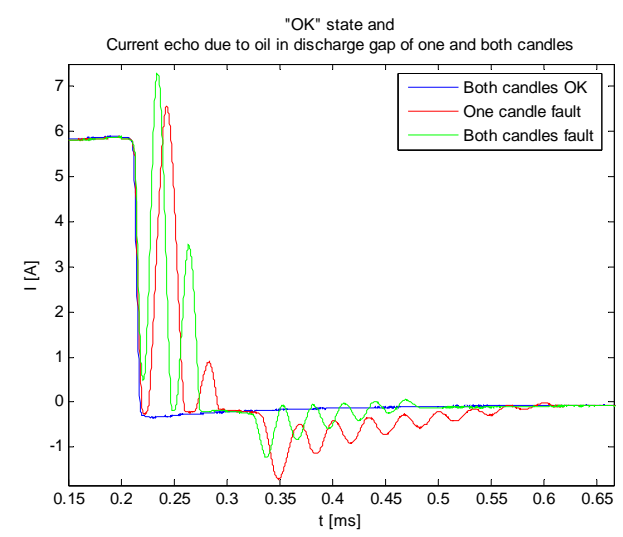

Fig. 8 - Two kinds of faults on engine lighting equipment real model expression.

One way of measurement circuit diagram is shown in Fig.9.

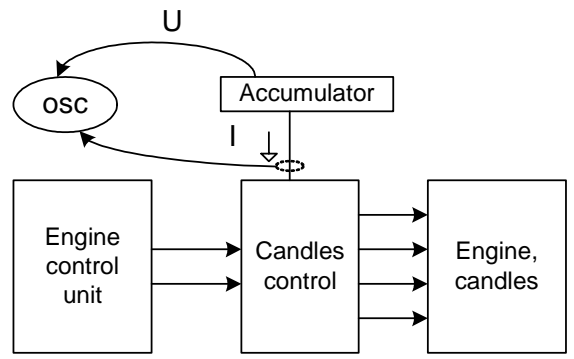

Fig. 9 Measurement circuit diagram.

\section{SIGNAL PROCESSING METHOD}

Commonly known short time Fourier transform is used to investigate the real condition of transformer-cable-spark configuration. The power dissipation in primary circuit caused by faults is similar to the damped oscillations. The basic frequency of these oscillations is minimally ten times higher than every other signal sources in a whole engine group. The highest sensitivity of STFT to reflecting signal can be reached using STFT window length equal to basic period of oscillations. The information about the kind of the fault is hidden in phase and amplitude spectrum (Fig.10) of the damped wave. The fault classifier can use fix threshold over the fix set of harmonic frequencies of spectra. Some pre-time-localization technique of candle lighting should be used to cancel the noise and superposition of power net influences of other devices. The simplest is using a threshold, because the current peaks generated by candles have higher amplitude than additional signal parts [1].

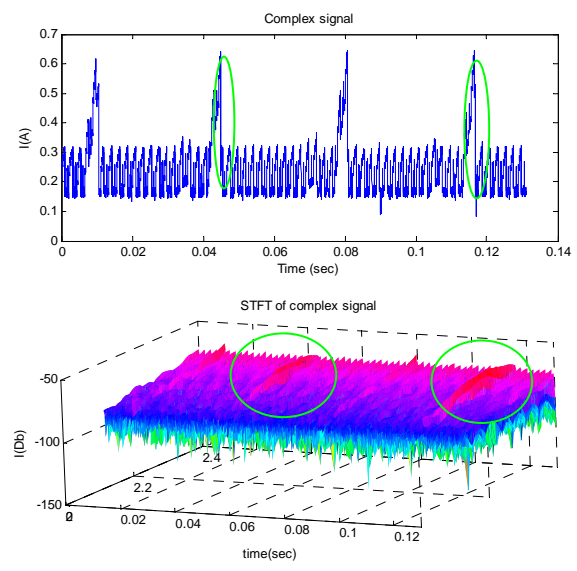

Fig. 10 - STFT of current signal through whole engine electrical parts.

The measurement on a SIC ignition systems in other car has really similar and usable results.

\section{CONCLUSIONS}

STFT method of signal preprocessing for obtaining the quality attributes was designed and tested. It is commonly known and relatively simple, but in this application it provides really plausible results. The method will be extended with statistic classifier to provide the complex diagnosis in a future.

Using this method supposes presence of the current and voltage dumped transients in the primary circuit of ignition system due to the faults in the engine lighting equipment. These transients have the basic harmonic frequency minimally one order higher than all other. Higher basic frequency is suitable for STFT usage or CWT (Complex wavelet transform), which usage is planned in future. The CWT can bring better faults discrimination than STFT in case of finding and using suitable mother 
wavelet.

\section{ACKNOWLEDGMENT}

This research was supported by the Czech Ministry of Education project No. 1M0568

\section{REFERENCES}

[1] Richard O. Duda, Peter E. Hart, David G.Stork, Pattern Classification $2^{\text {nd }}$ edition, John Wiley \& sons, Inc, New York, 2001. ISBN 0-47105669-3.

[2] Jakub Král, Petr Jezdik, Analýza chování zapalovacího ústroji vautomobilu Škoda (in Czech), study independent thesis, November 2006.

[3] Doc.RNDr. Pavel Kubě̌, CSc.,doc.RNDr. Zdeněk Kyncl, DrSc. Fyzika 1, Vydavatelství ČVUT, Zikova 4, 16635 Praha 6.

[4] Doc. Marcel Kreidl a kolektiv Diagnostické systémy, Vydavatelství ČVUT, Zikova 4, 16635 Praha 6.

[5] Intusoft Newsletter, Personal Computer Circuit \& System Design Tools, Issue\#50 Sept. 1997 pp.9-12

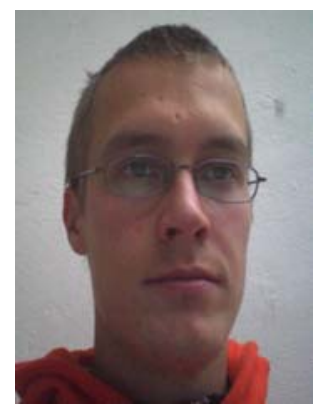

Petr Ježdík, since 2005 postgraduate student at Czech Technical University in Prague at Department of Measurement, laboratory of diagnostics. He received master degree at the same department in 2005 with diploma thesis subject " $C C D$ linear camera with mixed signal processing" at

laboratory of videometry. He worked at Instituto Superior Técnico Lisboa on project of nondestructive testing of aircraft materials in 2006. Currently he is working on project of Centralised diagnostic methods of electric devices in vehicles.
This research includes digital signal processing, diagnostic and simulation.

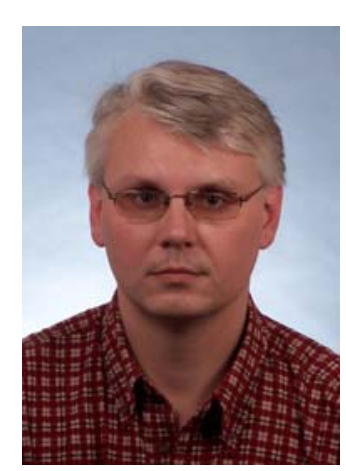

Jiři Novák, received his master and Ph.D. degrees at Czech Technical University of Prague at the Department of Measurement in years 1990 and 2000 respectively. His research activities are focused on test and diagnostics methods of vehicle electronic systems, especially the vehicle distributed systems, EMC and embedded systems design. He lectures several subjects focused on design and measurement methods in high-speed digital systems and industrial distributed systems. 